Int. J. Electrochem. Sci., 14 (2019) 5086 - 5095

\title{
Nanomolar Quantification of Polydatin at Boron Doped Diamond Electrode. Application in Dietary Supplements
}

\author{
Slađana Đurđićl, ${ }^{1,}$, Vesna Vukojević ${ }^{2}$, Miloš Ognjanović ${ }^{3}$, Lubomir Švorc ${ }^{4}$, Jelena Mutićl, \\ Dalibor M. Stanković ${ }^{3}$ \\ ${ }^{1}$ Faculty of Chemistry, University of Belgrade, POB 51, 118, 11158 Belgrade, Serbia \\ ${ }^{2}$ Institute of Chemistry, Technology and Metallurgy, University of Belgrade, Njegoseva 12, 11000 \\ Belgrade, Serbia \\ ${ }^{3}$ The Vinča Institute of Nuclear Sciences, University of Belgrade, POB 522, 11001 Belgrade, Serbia \\ ${ }^{4}$ Institute of Analytical Chemistry, Faculty of Chemical and Food Technology, Slovak University of \\ Technology in Bratislava, Radlinského 9, Bratislava, SK-812 37, Slovak Republic \\ *E-mail sladjanadj@chem.bg.ac.rs
}

doi: $10.20964 / 2019.06 .01$

Received: 3 February 2019 / Accepted: 27 March 2019 / Published: 10 May 2019

In this research we demonstrated detailed electrochemistry polydatin. Polydatin is a natural compound with expressed antioxidant activity. Electrochemical behavior of polydatin was tested in the potential range from $-1.5 \mathrm{~V}$ to $2 \mathrm{~V}$ at unmodified boron doped diamond electrode in various $\mathrm{pH}$ of supporting electrolyte. It has been noticed that polydatin provides two oxidation peaks, one at around $0.73 \mathrm{~V}$ and second at around 1.3 V. In the reverse scan no reduction peak was observed. Quantification of polydatin was done based on first oxidation peak using square wave voltammetry. After optimization of the method, linear working range from $1 \cdot 10^{-7} \mathrm{M}$ to $7 \cdot 10^{-5} \mathrm{M}$ was obtained, with limit of detection and limit of quantification of $6 \cdot 10^{-9} \mathrm{M}$ and $2 \cdot 10^{-8} \mathrm{M}$, respectively. Negligible interferences effects were noticed. Developed method shows excellent accuracy and precision toward detection of polydatin. Also, developed method was used for quantification of polydatin in dietary supplements.

Keywords: boron doped diamond electrode; dietary supplements; polydatin.

\section{FULL TEXT}

(C) 2019 The Authors. Published by ESG (www.electrochemsci.org). This article is an open access article distributed under the terms and conditions of the Creative Commons Attribution license (http://creativecommons.org/licenses/by/4.0/). 